\title{
Estado e sociedade civil em Gramsci: notas para discutir a institucionalização das demandas sociais no capitalismo e a dimensáo social da terapia ocupacional
}

\author{
State and civil society in Gramsci: notes to discuss the \\ institutionalization of social demands in capitalism and the social \\ dimension of occupational therapy
}

Waldez Cavalcante Bezerra ${ }^{\mathrm{a}}$ (D), Beatriz Prado Pereira ${ }^{\mathrm{b}}$ (D), Iara Falleiros Braga ${ }^{\mathrm{b}}$ (D)

aUniversidade Estadual de Ciências da Saúde de Alagoas - UNCISAL, Maceió, AL, Brasil.

bUniversidade Federal da Paraíba - UFPB, João Pessoa, PA, Brasil.

Como citar: Bezerra, W. C., Pereira, B. P., \& Braga, I. F. (2021). Estado e sociedade civil em Gramsci: notas para discutir a institucionalização das demandas sociais no capitalismo e a dimensão social da terapia ocupacional. Cadernos Brasileiros de Terapia Ocupacional. 29, e2048. https://doi.org/10.1590/2526-8910.ctoEN2048

\begin{abstract}
$\underline{\text { Resumo }}$
O objetivo deste ensaio foi trazer ao debate a concepção gramsciana de Estado e sociedade civil na tentativa de elencar elementos teóricos para discutir a terapia ocupacional no processo de institucionalização das demandas sociais no contexto de uma sociedade capitalista. Para tanto, recorreu-se a textos de autores que têm se dedicado ao estudo da obra de Gramsci, os quais possibilitaram uma análise crítica e a percepçáo da peculiaridade da concepçáo de Estado neste autor, pela incorporaçáo da sociedade civil, e as determinaçóes gerais da sua teoria. Nesse contexto, foi possível fazer apontamentos sobre a dimensão social da terapia ocupacional, como profissão que surge na e para a sociedade capitalista, com a função social de responder às demandas sociais de pessoas e grupos que encontram limitaçóes para participar da vida em sociedade, muitas delas decorrentes das contradiçôes próprias dessa sociedade. Reforça-se a necessidade do compromisso éticopolítico da profissão com os interesses coletivos das classes subalternas, principais demandantes do trabalho profissional.
\end{abstract}

Palavras-chave: Sociedade Civil, Capitalismo, Terapia Ocupacional.

\section{$\underline{\text { Abstract }}$}

The objective of this essay was to debate the Gramscian conception of the state and civil society, in an attempt to raise theoretical elements to discuss occupational therapy in the process of institutionalizing social demands in the context of a 
capitalist society. For that, we resorted to texts by authors who have been dedicating to the study of Gramsci's work, which allowed a critical analysis and the perception of the peculiarity of the conception of State by this author, through the incorporation of civil society and the general determinations of his theory. In this context, it was possible to make notes on the social dimension of occupational therapy, as a profession that emerges from and for the capitalist society, with the social function of responding to the social demands from people and groups that find limitations in participating in life in society, many of them arising from the contradictions inherent from this society. We reinforce the need for ethical and political commitment of occupational therapy professionals to the collective interests of the subordinate classes, which is the main demand of professional work.

Keywords: Civil Society, Capitalism, Occupational Therapy.

\section{Introduçáo}

No Brasil atual, cenário de ascensão política da extrema direita, observam-se severas ameaças às garantias constitucionais de 1988, as quais representaram um marco histórico na institucionalização de um conjunto amplo de demandas sociais, resultado das lutas políticas que tensionaram o Estado brasileiro no contexto de crise do regime ditatorial e possibilitaram a redemocratização do país na década de 1980. Assim, desde então, a sociedade civil e seus aparelhos ganharam maior liberdade de ação e reivindicação diante do Estado, principalmente quando se trata de temas como controle social sobre as políticas públicas, terceiro setor, organizaçóes não governamentais, movimentos sociais e a relação destes com o Estado e a administração pública.

Reconhecendo, portanto, o papel decisivo dos organismos sociais e políticos da sociedade civil diante do aparelho de Estado, nos diferentes momentos históricos, para a institucionalização ou não das demandas colocadas no cenário político pelas classes subalternas e transformação delas em direitos sociais, coloca-se a necessidade de revisitar teoricamente as categorias Estado e sociedade civil para uma melhor compreensão do tema em discussão e propor reflexôes sobre a dimensão social da terapia ocupacional. Tendo em vista a diversidade de perspectivas teóricas possíveis para a análise dessas categorias, tomar-se-á aqui aquela desenvolvida pelo intelectual e militante italiano, Antonio Gramsci, considerando a originalidade das suas formulaçóes e a influência que o seu pensamento possui na terapia ocupacional brasileira, sobretudo a partir da década de 1980.

Em um primeiro momento, buscar-se-á sumariar, ainda que resumidamente, os principais elementos que conformam a concepção de Estado e sociedade civil no interior da teoria gramsciana para, em seguida, discutir a institucionalização das demandas sociais no contexto do capitalismo e a dimensão social da terapia ocupacional, como profissão cuja ação se inscreve, majoritariamente, no campo de atuação do Estado, via políticas sociais, sendo inserida para trabalhar na implementação, execução e reconhecimento das necessidades da população (Bezerra \& Trindade, 2013; Lopes, 2016; Malfitano, 2016; Oliveira et al., 2019). 
Cabe enfatizar que não se pretende, e nem seria possível, esgotar com este texto a temática em discussão e nem desconsiderar a contribuição de outros/as terapeutas ocupacionais que buscaram pensar a profissão com base nas ideias de Gramsci. A proposta é trazer mais elementos para o debate teórico no âmbito da profissão.

\section{A Concepçáo de Estado e Sociedade Civil em Gramsci}

Inicialmente, julga-se necessário compreender o contexto no qual Gramsci formula suas ideias e porque ele se debruça tanto na esfera da política quanto cultural. Nascido em Sardenha, na Itália, em 22 de janeiro de 1891, Antonio Gramsci estudou em Turim, onde ingressou no Partido Socialista Italiano, em 1913, e participou da fundação do Partido Comunista Italiano (PCI), em 1921, que era parte integrante da Internacional Comunista, a chamada III Internacional. Durante o período do regime fascista na Itália, foi preso e condenado a 20 anos de prisão, onde produziu, sob condiçóes bastante adversas, sua obra de maturidade, materializada em 33 cadernos de tipo escolar, que foram resgatados do cárcere fascista por Palmiro Togliatti, secretário do PCI, com a ajuda de Tatiana Schucht, cunhada de Gramsci, e posteriormente publicada como Cadernos do Cárcere. Depois de adoecer na prisão, Gramsci morreu em 27 de abril de 1937 de uma hemorragia cerebral (Sader, 2005).

Nesse cenário, Gramsci vivenciou uma situação histórica peculiar, cujas questóes se referem à crise do Estado liberal e à hegemonia do sistema capitalista. Viveu em uma época em que o fenômeno estatal se complexificou pela intensificação dos processos de socialização e participação política, pela formaçáo de sindicatos, dos partidos de massas e pela conquista do sufrágio universal. Foi, portanto, nesse contexto de complexificação das relaçóes entre Estado e sociedade presentes na sua época que ele elaborou sua concepção de Estado Integral, ou, como ficou conhecido posteriormente, "Estado ampliado", após a publicação da obra seminal de Christinne Buci-Glucksmann, Gramsci e o Estado, originalmente publicada em francês em 1975 e em português em 1980 (Buci-Glucksmann, 1980).

Nos Cadernos do Cárcere, Gramsci chama atenção para o fato de que a relação entre Estado e sociedade civil possui um caráter orgânico, isto é, o Estado é integral porque mantém relaçóes inseparáveis com os aparelhos e as organizaçôes da sociedade civil, de modo que a separação entre ambos somente pode ser puramente metodológica. Estado e sociedade civil estão, portanto, em uma relação de unidade e distinção (Bianchi, 2008, p. 183). Neste sentido, ambos possuem aparelhos que os definem e distinguem, no entanto, suas relaçóes constituem organicamente a base do poder de Estado. O próprio Gramsci atentou para este fato, quando afirmou no Caderno 4 que:

[...] especula-se inconscientemente [...] sobre a distinçáo entre sociedade política e sociedade civil e se afirma que a atividade econômica é própria da sociedade civil e a sociedade política não deve intervir na sua regulamentação. Mas, na realidade, essa distinção é puramente metodológica, mas não orgânica (Gramsci apud Liguori, 2007, p. 16).

Nessa direção, Correia (2005, p. 9) afirma que o pensamento de Gramsci tem como eixo de análise do real a perspectiva de totalidade, “[...] em que subverte os princípios do determinismo econômico, do politicismo, do individualismo e do ideologismo [...]", 
e estabelece uma conexão dialética entre estrutura e superestrutura, concebendo a realidade, assim como Marx, como síntese de múltiplas determinaçóes.

Para Semeraro (2011, p. 473), em Gramsci “[...] não é possível separar Estado e sociedade civil, nem identificar os dois [...]", pois, embora distintos, ambos estão intimamente ligados, do mesmo modo que a "[...] sociedade política e sociedade civil são componentes constitutivos e inseparáveis do Estado". A sociedade política se estabeleceria pela arena das instituiçóes políticas e do controle legal constitucional que compreende os aparelhos de coerção e repressão do Estado (exército, a polícia, a administração pública, os tribunais), ou seja, seria formada pelo conjunto dos mecanismos por meio dos quais a classe dominante detém o monopólio legal da repressão e da violência. Já a sociedade civil corresponderia a uma esfera "privada" ou "nãoestatal", constituída pelo conjunto de organizaçooes responsáveis pela elaboração e/ou difusão das ideologias, compreendendo as escolas, as igrejas, os partidos políticos, os sindicatos, as organizaçôes profissionais, os meios de comunicação etc. É, portanto, no âmbito da sociedade civil que se formariam as consciências em torno da aceitação ou não da ordem vigente.

Nesse sentido, os aparelhos privados de hegemonia consistem em importante instrumento conceitual para compreensão da relação entre sociedade civil e Estado. Por meio destes aparelhos, as classes disseminam sua visão de mundo e formam um consenso em torno dela (Liguori, 2007), caminho para manutenção da hegemonia dos grupos que já dominam ou para a construção de uma nova hegemonia.

Em Gramsci, a hegemonia pode ser entendida como a capacidade de "direção intelectual e moral" que um grupo social exerce sobre os demais e sobre a sociedade como um todo; em outros termos, significa quando um grupo ou classe social consegue estabelecer a sua vontade como fundamento da organizaçáo dos diversos setores sociais em torno do seu projeto de sociedade (Cavalcante, 2008). Assim, a hegemonia não é uma ação partidária, mas uma ação de classe, que apresenta os interesses de um grupo social como sendo para todos, auxiliando na manutenção do status quo e, na sociedade capitalista, na subjugação dos trabalhadores perante os donos dos meios de produção. Nessa direçáo, Gramsci propóe a necessidade de construir uma contra-hemegonia, em oposiçáo ao capitalismo, que tenha como base a visão de mundo $e$ as necessidades das classes subalternas.

Para que uma classe se torne dominante, ela deve, antes. tornar-se dirigente, isto é, Gramsci observa que o Estado não se assenta somente sobre a força, o monopólio legítimo da violência, mas sua autoridade se baseia num "equilíbrio dinâmico" entre força e consenso (Bianchi \& Aliaga, 2011). Deste modo, toda dominação estatal carrega em si também o elemento do consenso, da direção política. Destarte, no exercício normal da democracia parlamentar, é possível afirmar que o Estado se assenta em uma "hegemonia couraçada de coerção" (Gramsci, 2000a, p. 244). O autor reconhece que o Estado atua como instrumento essencial para expandir o poder da classe dominante, tanto por meio da difusão dos valores e da visão de mundo desta classe quanto por meio da força repressiva que visa a manter os grupos subordinados fracos e desorganizados.

$\mathrm{O}$ entendimento do Estado enquanto aparelho de repressáo e dominação de uma classe sobre a outra corresponde, na teoria de Gramsci, portanto, a apenas um momento da composição do Estado, o da sociedade política. Assim, o Estado em Gramsci não se restringe aos aparelhos repressivos, mas estende-se também aos aparelhos de hegemonia, uma vez que a complexificação das formaçôes sociais ocidentais colocou a necessidade de a classe hegemônica buscar outros meios de manter sua hegemonia que não fosse só pelo uso da força. O Estado consiste, ainda, em "[...] todo o complexo de atividades práticas e teóricas com os quais a classe 
dirigente năo só justifica e mantém o seu domínio, mas consegue obter o consenso ativo dos governados" (Gramsci, 2000a, p. 331).

Diferente das concepçôes de Hegel e Marx, Gramsci situa a sociedade civil como um momento da superestrutura e não ao da estrutura ${ }^{1}$, embora ainda reconheça a centralidade da base material ao entender que os aparelhos privados de hegemonia da sociedade civil estão também ligados ao mundo da economia, ao contrário das interpretaçôes deterministas realizadas por alguns autores ${ }^{2}$ sobre o pensamento gramsciano.

Fazendo uma leitura não economicista de Marx para combater o determinismo econômico atribuído a este, Gramsci desenvolve seu pensamento sobre a relação entre estrutura e superestrutura, unindo-as em uma totalidade social que denominou de "bloco histórico". Para ele, as superestruturas se complexificam e, em última instância, são determinadas pela estrutura econômica, mas não em uma relação mecânica $\mathrm{e}$ automática, pois, entre elas, há uma dessincronia decorrente das singularidades históricas (Correia, 2017). A conexão entre essas duas esferas pode ser observada na discussão de Gramsci sobre o americanismo e fordismo e, de forma bem clara, quando ele afirma "[...] que não pode existir igualdade política completa e perfeita sem igualdade econômica [...]” (Gramsci, 2000a, p. 224).

Ainda no combate ao economicismo, inibidor da crítica e da ação das classes, Gramsci reafirma a importância da atividade política na determinação de programas de reforma, sem, contudo, cair no politicismo. Rompe, assim, com o pensamento determinista econômico que atribui somente às forças produtivas, no sentido restrito de tecnologia, o papel de motor da história.

Em seu pensamento, a disputa pela hegemonia se dá no âmbito e por meio da sociedade civil, onde as classes buscam ganhar aliados para suas posiçóes mediante a direção política e o consenso. Semeraro (2011, p. 474) coloca que, em Gramsci, a sociedade civil náo seria apenas "[...] o âmbito das liberdades individuais e das atividades econômicas" [...], mas é também "[...] o lugar das diversas organizaçóes voluntárias, da elaboração de ideologias e culturas, da formaçâao de subjetividades, dos embates políticos, das mobilizaçóes populares".

Nesse sentido, a sociedade civil não se constitui como um todo homogêneo, mas como um espaço onde existem interesses conflitantes e de disputa pela hegemonia; e sendo, portanto, a sociedade civil constituinte também do Estado, este por sua vez é permeado pelos interesses e conflitos das classes que constituem a estrutura econômica.

A sociedade civil náo é homogênea, mas espaço de lutas de interesses contraditórios. As lutas não são da sociedade civil contra o Estado, mas de setores que representam os interesses do capital e do trabalho [...] na sociedade civil e no Estado na busca da hegemonia. [...] enquanto integrante da totalidade social tem um potencial transformador, pois nela também se processa a organização dos movimentos sociais que representam os interesses das classes subalternas na busca da 'direçáo políticoideológica' (Correia, 2005, p. 14).

\footnotetext{
${ }^{1}$ No método materialista histórico e dialético, de um modo geral, a estrutura se refere ao conjunto das relaçôes de produção de uma sociedade, à esfera da economia. Sobre esta estrutura econômica, ergueria-se uma superestrutura, que se refere às formas de consciência social, como a política, a cultura, as ciências, as religióes, as artes, as visóes de mundo e demais componentes ideológicos de uma classe.

${ }^{2}$ Faz-se referência à distorção realizada por Bobbio (1997) ao identificar, erroneamente, uma cisão entre os elementos estruturais e superestruturais no pensamento de Gramsci.
} 
É por esse entendimento que Montańo (2007) afirma que não seria correto se referir às lutas da sociedade civil, mas sim às lutas na sociedade civil. Segundo o autor, compreender a sociedade civil como um todo harmônico e homogêneo, na qual existiriam apenas interesses comuns, leva à uniformização de uma esfera essencialmente heterogênea e contraditória, pois, na sociedade civil, estão presentes tanto organizaçôes dos trabalhadores quanto do capital; pensar nela como uniforme resulta em um erro de interpretação histórica. Problematizando ainda mais esse equívoco, o autor acrescenta que "[...] pensar nas 'lutas da sociedade civil' remete também, e fundamentalmente, a pensar esta esfera social não como espaço de lutas, mas como sujeito delas [...]" (Montaño, 2007, p. 275).

Observa-se, desse modo, que na visão de Gramsci não existe espaço para compreender o Estado e a sociedade civil como esferas homogêneas, como esferas que representam interesses de uma mesma classe, como muitas vezes a sociedade civil tem sido colocada, ideologicamente, por alguns teóricos, e como aparece no senso comum na atualidade. Pelo contrário, na perspectiva gramsciana náo se pode tomar o Estado e a sociedade civil como blocos monolíticos, mas como espaços permeados pela luta de classes em que as classes subalternas devem disputar a sua hegemonia.

Sendo assim,

Gramsci defende a possibilidade de que mecanismos consensuais e contratuais resultantes de açóes sociais conscientes e críticas podem cada vez mais ser criados, consolidados e desenvolvidos, particularmente no campo da política. $\mathrm{O}$ autor insiste na idéia de que a constituiçẫo de uma hegemonia das classes subalternas [...] requer uma intensa 'preparação ideológica das massas', um 'trabalho de crítica, de penetração cultural, de penetração de idéias', de construçáo de uma nova concepçáo de mundo (Duriguetto, 2007, p. 62).

Ganha, então, destaque o papel do intelectual orgânico na teoria do autor, enquanto aquele que exerce a função de organizar, dirigir e educar, seja no terreno da produçáo, da cultura, da política ou da administração. Sua tarefa principal, segundo Duriguetto (2007, p. 64), “[...] consiste em estabelecer os nexos nos caracteres difusos e dispersos do 'senso comum' das classes subalternas para uma elaboração superior de sua visão de mundo, para uma construção ativa de sua própria história”.

A compreensão de intelectual em Gramsci não está limitada às atividades intrínsecas de uma determinada forma de trabalho (domínio de teorias, de uma linguagem científica, conhecimento de metodologias de pesquisa etc.), mas sim à função que o indivíduo assume no conjunto das relaçóes sociais, pois, segundo o autor, "o operário [...] não se caracteriza especificamente pelo trabalho manual ou instrumental, mas por este trabalho em determinadas relaçóes sociais [...]" (Gramsci, 2014, p. 18). Com isso, ele amplia a noção de intelectual rompendo com a dicotomia entre sujeitos cultos e incultos, de modo que qualquer sujeito pode assumir o papel de intelectual orgânico.

$\mathrm{Na}$ concepção gramsciana, todo intelectual está comprometido com alguma visão de mundo, ou seja, inexiste intelectual que não esteja vinculado a um projeto político ideológico, tenha ele consciência disto ou não. Ou ele exerce a sua atividade ideológica a favor da legitimação do poder dos grupos dominantes ou a desempenha em função da transformação social em favor dos grupos subalternos e da construçáo de um novo projeto societário. Santos (2017) afirma que o intelectual pode ser conservador na 
medida em que adere à política da classe dominante, mas também pode se assumir como revolucionário/orgânico quando se vincula ao horizonte político da classe trabalhadora.

\section{Contribuiçóes de Gramsci para o Entendimento da Institucionalizaçáo das Demandas Sociais e da Dimensáo Social da Terapia Ocupacional}

No contexto da sociedade capitalista, entende-se que as demandas sociais se originam a partir das necessidades sociais que são produzidas pelas contradiçóes imanentes dessa sociedade e que nesta ordem não podem ser atendidas totalmente, visto que seu objetivo é o atendimento das necessidades econômicas do sistema, em detrimento das necessidades humano-sociais dos trabalhadores. Contudo, reconhece-se que há um campo político de lutas e que, a depender da correlação de forças, o Estado pode ser mais ou menos favorável à institucionalização das demandas sociais e aos interesses e necessidades das classes subalternas.

Assim, no contexto atual de crise capitalista, várias são as mudanças empreendidas pelo capital na tentativa de superá-la, em sua maioria, com repercussóes negativas para a classe trabalhadora, no sentido de restringir a conquista ou a manutenção dos direitos sociais. Além de novos padróes econômicos, chegam à cena novos valores e regras de comportamento, a fim de atender às necessidades da produção e reproduçáo capitalista, porém, mantendo as marcas da dependência, da exclusão social, dos índices de desemprego e de precarização do trabalho (Santos, 2013).

Como parte dessas mudanças, disseminam-se, no campo ideológico, concepçóes fragmentadas e superficiais sobre os mais diversos aspectos da vida social, em que proposiçóes críticas (a exemplo do marxismo) passam a ser alvo de ataques, numa clara tentativa de desvalorização dessas ideias, como se as contradiçōes e antagonismos imanentes dessa sociedade tivessem sido superadas. A recente eleição presidencial no Brasil e a vitória nas urnas do candidato Jair Bolsonaro, em 2018, que conseguiu apoio de grande parte da sociedade com uma campanha com conteúdo conservador, criminalizador dos movimentos sociais, de ataque aos direitos sociais, com a defesa da restrição de direitos civis e políticos de grupos vulneráveis; e o aumento do poder de ação e veto dos setores religiosos fundamentalistas, é emblemática desse processo (Quinalha, 2016; Gallego, 2018).

Observam-se tentativas constantes de fragmentar, desmobilizar e desmoralizar os movimentos sociais oriundos das classes subalternas, com o intuito de manter a hegemonia das classes dominantes. É nesse sentido, em particular, que a teoria gramsciana sobre o Estado e a sociedade civil se mostra necessária à discussão sobre a institucionalização das demandas sociais na sociedade capitalista, uma vez que essa institucionalizaçáo ocorre a partir da correlaçáo de poder e forças entre as classes sociais, que buscam exercer sua hegemonia nos diferentes momentos históricos.

Nessa perspectiva, entende-se o Estado e a sociedade civil como espaços contraditórios da luta de classes, nos quais as classes subalternas, organizadas politicamente, podem disputar a hegemonia por um novo projeto societário ou, ainda nessa sociedade, reivindicar a institucionalização das suas demandas e ampliar os direitos sociais. Portanto, sob as proposiçóes gramscianas de que a vida em sociedade é produto da ação humana, considerando as condições objetivas de cada momento histórico, coloca-se a possibilidade desses sujeitos imprimirem sua consciência e vontade na transformação da realidade. 
Um aspecto de extrema importância na teoria gramsciana de Estado e sociedade civil para a discussão das demandas sociais - envolvendo a ampliação ou retração dos direitos sociais - diz respeito à compreensão dessas esferas como espaços heterogêneos e cheio de contradiçóes, pois, isto abre a possibilidade das classes subalternas construírem seu projeto societário e disputarem a hegemonia no interior dessas esferas, alargando as possibilidades de atendimento às suas necessidades.

Outro aspecto diz respeito à centralidade da discussão acerca do papel do intelectual na sociedade contemporânea. São intelectuais orgânicos aqueles que, além de especialistas na sua profissão, estão vinculados ao modo de produção, sob uma concepção ético-política que os habilita a exercer funçóes culturais, educativas e organizativas, assegurando a hegemonia social. Conscientes de seus vínculos de classe, manifestam sua atividade intelectual, atuando nos processos de formação de consciência crítica, a partir de uma relaçáo orgânica com a classe que se identificam. Assim, para Gramsci, a organicidade dos novos intelectuais está relacionada principalmente à sua profunda vinculação à cultura, à história e à política das classes subalternas que se organizam para construir uma nova civilização (Semeraro, 2006).

Desse modo, o intelectual orgânico se distancia daquele que pretende validar a ordem social burguesa vigente, buscando, por meio da sua ação, desvelar os condicionamentos históricos que, absorvidos acriticamente, em função da ação das instituiçôes e organizaçóes do Estado e da sociedade civil, limitam o poder de luta das classes subalternas.

Para não retirar a primazia ontológica da base material, enfatizamos que, no pensamento de Gramsci, a reforma intelectual e moral deve estar articulada a uma reforma econômica, na qual "[...] o avanço da democratização política é, ao mesmo tempo, condição e resultado de um processo de transformação também nas esferas econômica e social [...]" (Gramsci, 2000b, p. 19). Assim, fica claro que a luta de classes e a possibilidade de superação desta sociedade permanecem presentes.

Feitas essas consideraçóes, cabe-nos fazer alguns apontamentos sobre o lugar do/a terapeuta ocupacional nesse processo complexo e contraditório, que é a institucionalização das demandas sociais na sociedade capitalista. Parte-se, aqui, do princípio de que a terapia ocupacional, devido à sua forma de inserção na divisáo social do trabalho capitalista, participa do processo de reproduçáo social da sociabilidade burguesa, na medida em que atua, principalmente, por meio de políticas e serviços sociais estatais, sobre as expressóes da chamada questão social (Bezerra $\&$ Trindade, 2013).

Adotando uma concepção de terapia ocupacional que parte do entendimento de que a função social do/a terapeuta ocupacional nesta sociedade é atuar, em distintos campos, para promover e/ou ampliar a inserção e participação sociais de determinadas pessoas, coletivos e grupos, torna-se fundamental situar essa prática em um contexto social concreto. Essa concepção da profissão, que pode ser articulada à discussão acerca do papel do intelectual orgânico proposta por Gramsci, implica no reconhecimento de que, para além da aplicaçáo de técnicas específicas, o trabalho do/a terapeuta ocupacional deve estar articulado e voltado à dimensão social da vida das pessoas, um trabalho que comporta a inseparabilidade das dimensôes técnica, ética e política (Malfitano, 2016).

Cabe ressaltar que a discussão sobre a inseparabilidade dessas dimensões do trabalho profissional e sobre a função social da terapia ocupacional já se faz presente na categoria há algumas décadas. Soares (1991), ao discutir as determinaçóes econômicas, políticas e 
sociais da constituição da terapia ocupacional no Estado brasileiro no período de 1950 a 1980, revelou que a profissão, imersa nas relações de classe e fruto da divisão social do trabalho capitalista, participa do atendimento às necessidades da classe trabalhadora ao mesmo tempo em que essa ação se refuncionaliza para os interesses das classes dominantes. A autora afirma que, no Brasil, o papel ideológico reservado à terapia ocupacional naquele período reforçou dois aspectos fundamentais e indissociáveis do Estado brasileiro: o assistencialismo, visando dar uma face humanitária e democrática às relaçóes sociais de dominação; e o controle, utilizando-se de práticas científicas para travestir as verdadeiras problemáticas sociais (Soares, 1991). Na mesma direção, Lopes (1999) analisou o processo histórico da terapia ocupacional e cunhou a expressão "funcionários do consenso", fazendo referência ao pensamento de Gramsci, para explicitar as funçóes políticas e ideológicas que o trabalho profissional cumpriu em determinados momentos e contextos históricos.

Desse modo, pensar o cotidiano, a inserção e a participação sociais das pessoas com as quais trabalha, requer do/a terapeuta ocupacional a consideração de que vivemos em uma sociedade capitalista, estruturada sobre relaçôes desiguais e cujas mazelas não só são repostas continuamente, mas também impactam diretamente a vida das pessoas, limitando as possibilidades do viver com dignidade. Também requer considerar que as respostas institucionais para as demandas sociais apresentadas pelos grupos-alvo das açóes profissionais ocorrem, principalmente, via políticas sociais estatais, sendo estas a mediação principal de inserção e atuação do/a terapeuta ocupacional no mercado de trabalho.

Entendendo que as políticas sociais resultam da institucionalização de determinadas demandas sociais, fruto das tensóes e conflitos gerados no âmbito das relaçóes entre sociedade civil e Estado, nas quais a atuação dos movimentos sociais ocupa lugar de destaque, o trabalho do/a terapeuta ocupacional impóe a necessidade do/a profissional participar diretamente na arena pública de discussão de projetos e necessidades coletivas, com vistas ao alargamento dos direitos sociais que propiciam, aos sujeitos, um maior acesso aos bens e serviços e, consequentemente, uma maior inserção e participação na vida em sociedade (Malfitano, 2016). Assim,

[...] o terapeuta ocupacional não pode 'apenas' realizar uma atenção individualizada, restrita à aplicação de técnicas ou abordagens particularizadas, voltada para sujeitos ou grupos, pois isso não é suficiente para que alcance o propósito de sua ação: a inserção e participação sociais. Para que alcance este objetivo, é essencial a associação entre as dimensôes micro e macrossocial, entre uma análise técnica e política do local, do grupo populacional e dos sujeitos com os quais atua. $\mathrm{O}$ trabalho requer que se conciliem e se conectem as necessidades individuais, coletivas e institucionais (Malfitano, 2016, p. 121).

Nesse sentido, as proposiçóes de Gramsci acerca do Estado e da sociedade civil, bem como sobre o papel do intelectual orgânico nas lutas sociais para a transformação da realidade e da ocupação dos espaços na arena política, refuncionalizando-os em prol dos interesses das classes subalternas, mostra-se útil à discussão sobre a dimensão social da terapia ocupacional e o seu compromisso com os interesses coletivos.

Ao se propor trabalhar com o desenvolvimento da autonomia e emancipação das pessoas, reconhecendo-as como sujeitos de direitos sociais, defende-se aqui a necessidade 
de uma consciência política e social para as intervençóes profissionais, de modo que a terapia ocupacional assuma um compromisso ético-político com os interesses individuais, mas mais coletivos, sintonizando a sua teoria e prática com projetos societários voltados para a construção de uma nova hegemonia na relação entre as classes sociais, assumindo uma responsabilidade técnica para exercer um papel político a partir da sua prática, de forma consciente, decidindo entre o consenso e o dissenso, participando, técnica e politicamente, do movimento de transformação social (Lopes, 1996).

Considerando a dimensão ideopolítica do trabalho profissional, o referencial gramsciano pode sustentar uma prática em que o terapeuta ocupacional se reconheça como aquele que pode promover a elevação intelectual e moral dos beneficiários dos seus serviços, no sentido de despertar nestes a consciência crítica sobre as contradiçóes da realidade e mediar processos de construçáo da vontade coletiva das classes subalternas, mas reconhecendo que ambos (profissional e usuário) necessitam assumir uma postura ativa como sujeitos históricos. Isso implica romper com perspectivas e aportes teóricos que supõem uma concepção neutra da profissão e colocar no centro da discussão a perspectiva de classe, assumindo e demonstrando o compromisso profissional com a classe trabalhadora.

Nessa concepção de "projeto profissional", o/a terapeuta ocupacional não deve ficar alheio aos movimentos e lutas que se processam na sociedade, mas, sim, envolver-se na condição de sujeito-profissional inserido na dinâmica das relaçóes capitalistas, as quais colocam limites náo só à sua ação profissional, mas também aos modos de vida dos sujeitos e coletivos. Envolver-se nas lutas sociais preocupado não só com ampliação de direitos e acessos para os sujeitos e coletivos, mas também com a construção de novas relaçôes sociais e de um projeto político democrático e transformador, que, de fato, promova a emancipação humana.

\section{Conclusáo}

Com base no exposto, considera-se o constructo teórico de Gramsci um conjunto de ideias extremamente válidas não só para propor a transição para uma nova sociedade, mas também para analisar e compreender o desenvolvimento das sociedades capitalistas modernas. O autor desenvolve uma concepção de Estado e sociedade civil que contribui para o entendimento dos processos políticos e sociais envolvidos na institucionalizaçáo das demandas sociais na sociedade capitalista, colocando também para a classe trabalhadora uma nova possibilidade de superação da exploração rumo à emancipação humana, mostrando, assim, seu compromisso com as lutas das classes subalternas.

Nesse contexto, suas ideias possibilitam fazer apontamentos sobre a dimensão social da terapia ocupacional, como profissão que surge na e para a sociedade capitalista, com a função social de responder às demandas sociais de pessoas e grupos que encontram limitaçóes para participar da vida em sociedade, muitas delas decorrentes das contradiçōes próprias dessa sociedade. Com base na concepção de intelectual orgânico de Gramsci, reforça-se a necessidade do compromisso ético-político da profissão com os interesses coletivos das classes subalternas, principais demandantes do trabalho profissional.

Toda a construçâo teórica e prática da terapia ocupacional no Brasil se modificou e continua se modificando - ao longo dos tempos e da história e se coloca frente às demandas apresentadas pela sociedade, que também se modificam. Para nós, a validade 
analítica do pensamento gramsciano para as lutas que se colocam na contemporaneidade é inquestionável, bem como para as reflexóes sobre o papel técnico-profissional e a função social do/a terapeuta ocupacional, sobretudo em um momento que o capital, em decorrência de sua crise estrutural, eleva suas contradiçóes e desigualdades. Assim, o questionamento que fica é: como a terapia ocupacional tem se colocado (ou vai se colocar) frente a essas problemáticas sociais atuais?

\section{Referências}

Bezerra, W. C., \& Trindade, R. L. P. (2013). A terapia ocupacional na sociedade capitalista e sua inserção profissional nas políticas sociais no Brasil. Cadernos de Terapia Ocupacional da UFSCar, 21(2), 429437.

Bianchi, A. (2008). O laboratório de Gramsci. São Paulo: Alameda.

Bianchi, A., \& Aliaga, L. (2011). Força e consenso como fundamentos do Estado: pareto e Gramsci. Revista Brasileira de Ciência Politica, (5), 17-36. http://dx.doi.org/10.1590/S010333522011000100002.

Bobbio, N. (1997). Estado, governo e sociedade: para uma teoria geral da política. Rio de Janeiro: Paz e Terra.

Buci-Glucksmann, C. (1980). Gramsci e o Estado. Rio de Janeiro: Paz e Terra.

Cavalcante, M. P. (2008). Hegemonia e formação da vontade coletiva. In A. C. S. Vieira \& M. V. B. Amaral (Eds.), Trabalho e direitos sociais: bases para a discussão (pp. 95-121). Maceió: Edufal.

Correia, M. V. C. (2005). O Conselho Nacional de Saúde e os Rumos da Politica de Saúde Brasileira: mecanismo de controle social frente às condicionalidades dos organismos financeiros internacionais (Tese de doutorado). Universidade Federal de Pernambuco, Recife.

Correia, M. V. C. (2017). Gramsci e a crítica ao determinismo econômico na relaçăo entre estrutura e superestrutura. In A. Nascimento \& J. O. Leite (Eds.), Gramsci em perspectiva (pp. 11-24). Maceió: Edufal.

Duriguetto, M. L. (2007). Sociedade civil e democracia: um debate necessário. São Paulo: Cortez.

Gallego, E. S. (2018). Crise da democracia e extremismos de direita. Análise - Friedrich-Ebert-Stiftung Brasil, 1(42), 1-27.

Gramsci, A. (2000a). Cadernos do cárcere. (Vol. 3). Rio de Janeiro: Editora Civilização Brasileira.

Gramsci, A. (2000b). Cadernos do cárcere. (Vol. 2). Rio de Janeiro: Editora Civilizaçáo Brasileira.

Gramsci, A. (2014). Cadernos do cárcere: (Vol. 2: Os intelectuais. O Princípio educativo. Jornalismo). Rio de Janeiro: Civilizaçáo Brasileira.

Liguori, G. (2007). Roteiros para Gramsci. Rio de Janeiro: Editora UFRJ.

Lopes, R. E. (1996). A direção que construímos: algumas reflexôes sobre a formação do terapeuta ocupacional. Revista de Terapia Ocupacional da Universidade de São Paulo, 4(70), 27-35.

Lopes, R. E. (1999). Cidadania, politicas públicas e terapia ocupacional, no contexto das açóes de saúde mental e saúde da pessoa portadora de deficiência no município de São Paulo (Tese de doutorado). Universidade Estadual de Campinas, Campinas.

Lopes, R. E. (2016). Cidadania, direito e terapia ocupacional social. In R. E. Lopes \& A. P. S. Malfitano (Eds.), Terapia ocupacional social: desenhos teóricos e contornos práticos (pp. 29-48). São Carlos: EduFSCar.

Malfitano, A. P. S. (2016). Contexto social e atuação social: generalizaçôes e especificidade na terapia ocupacional. In R. E. Lopes \& A. P. S. Malfitano (Eds.), Terapia ocupacional social: desenhos teóricos e contornos práticos (pp. 117-134). São Carlos: EduFSCar. 
Montaño, C. (2007). Terceiro setor e questão social: crítica ao padrão emergente de intervenção social. São Paulo: Cortez.

Oliveira, M. L., Pinho, R. J., \& Malfitano, A. P. S. (2019). O cenário da inserção dos terapeutas ocupacionais no Sistema Único de Assistência Social: registros oficiais sobre o nosso percurso. Cadernos Brasileiros de Terapia Ocupacional, 27(4), 828-842.

Quinalha, R. (2016). "Em nome de Deus e da família”: um golpe contra a diversidade. In I. Jinkings, K. Doria \& M. Cleto (Orgs.), Por que gritamos golpe? Para entender o impeachment e a crise politica no Brasil (pp.112-117). São Paulo: Boitempo.

Sader, E. (2005). Gramsci: poder, politica e partido. São Paulo: Expressão Popular.

Santos, P. (2017). O intelectual orgânico como formador da vontade coletiva dos subalternos: apontamentos a partir de Antonio Gramsci. Movimento-revista de Educação, 4(6), 107-130.

Santos, R. S. (2013). Coronéis e empresários: permanência da dependência e da estrutura socioeconômica excludente no Brasil pós-Ditadura (1985-2002) (Dissertação de mestrado). Universidade do Estado do Rio de Janeiro, Rio de Janeiro.

Semeraro, G. (2006). Intelectuais “orgânicos” em tempos de pós-modernidade. Cadernos CEDES, 26(70), 373-391.

Semeraro, G. (2011). A “utopia” do Estado Ético em Gramsci e nos movimentos populares. Revista de Educação Pública, 20(44), 465-480.

Soares, L. B. T. (1991). Terapia ocupacional: lógica do capital ou do trabalho? São Paulo: Editora Hucitec.

\section{Contribuição dos Autores}

As reflexóes deste texto decorrem do trabalho final entregue por Waldez Cavalcante Bezerra na disciplina "Controle social sobre as políticas públicas e Serviço Social", do doutorado em Serviço Social do Programa de Pós-Graduação em Serviço Social da Universidade Federal de Alagoas (UFAL), sendo ele responsável pela concepção e redação do texto. Em construçáo teórica no Núcleo Metuia UFPB/Uncisal, Beatriz Prado Pereira e Iara Falleiros Braga trabalharam no processo de construção, redação e revisão do texto. Todos os autores aprovaram a versão final do texto.

\section{Autor para correspondência}

Waldez Cavalcante Bezerra

e-mail: waldezto@yahoo.com.br

\section{Editora de seçáo}

Ana Paula Serrata Malfitano 